九州大学学術情報リポジトリ

Kyushu University Institutional Repository

A Simple and Rapid Method to Measure Residue of Cefexime - a Cephalosporin Antibiotic in the Wastewater of Pharmaceutical Production Plant

Hue, Tran Thi Thanh

National Institute of Drug Quality Control

Son, Doan Cao

National Institute of Drug Quality Control

Anh, Nguyen Thi Lan

Hano i University of Pharmacy

Phong, Thai Khanh

National Research Centre for Environmental Toxicology, University of Queensland

他

https://doi.org/10.5109/1434408

出版情報: 九州大学大学院農学研究院紀要. 59 (1)，pp.169-175，2014-02-28. Faculty of Agriculture, Kyushu University

バージョン：

権利関係 : 


\title{
A Simple and Rapid Method to Measure Residue of Cefexime - a Cephalosporin Antibiotic in the Wastewater of Pharmaceutical Production Plant
}

\section{Tran Thi Thanh HUE ${ }^{1}$, Doan Cao SON ${ }^{1}$, Nguyen Thi Lan ANH $^{2}$, Nguyen Thi Kieu ANH ${ }^{2 *}$, Thai Khanh PHONG ${ }^{3}$ and Kazuaki HIRAMATSU}

\author{
Laboratory of Water Environment Engineering, Division of Bioproduction Environmental Sciences, \\ Department of Agro-Environmental Sciences, Faculty of Agriculture, \\ Kyushu University, Fukuoka 812-8581, Japan \\ (Received October 31, 2013 and accepted November 11, 2013)
}

\begin{abstract}
A simple and rapid HPLC method was developed to analyse cefixime, and potentially other cephalosporin antibiotic in wastewater of pharmaceutical production industry. The collected wastewater samples were treated by liquid - liquid extraction using chloroform to eliminate contaminants before instrumental analysis. Separation of the analyte was achieved using a Phenomenex Luna C18 column $(250 \times 4.6 \mathrm{~mm}$; $5 \mu \mathrm{m})$ and a mixture of methanol and phosphate buffer $\mathrm{pH} 3.2$ as mobile phase in a gradient program. The drug was detected by UV detector at wavelength of $285 \mathrm{~nm}$. The analytical method was first validated using cefixime- spiked samples. Absorbance response to cefixime concentrations is linear from 23 to $1100 \mathrm{ppb}$ with a correlation coefficient $>0.999$ and the limit of detection of $6.68 \mathrm{ppb}$. Repeatability and intermediate precision were tested with RSD of less than $3.0 \%$. The recovery values were found in the range of $97.4-$ $106.0 \%$. The method was then applied to determine concentrations of cefixime in real wastewater samples. The concentrations of cefixime residue measured in the actual samples were in the range of 19.24 to $43.33 \mathrm{ppb}$ which proved the applicability of this analytical method in monitoring the level of contaminated cefixime from the effluent of the pharmaceutical manufacturing plant into environment. The method also showed a potential to apply for other cephalosporin antibiotics.
\end{abstract}

Key words: cefixime, environmental monitoring, HPLC, water quality

\section{INTRODUCTION}

Antibiotics are extensively used in human and veterinary medicine, as well as in aquaculture, for the purpose of preventing (prophylaxis) or treating microbial infections (Kümmerer, 2009a). Although antibiotics are important for the protection of human and animal health from bacterial infections the presence of antibiotic residues in the general aquatic environment may cause an unexpected problem - bacterial resistance to antibiotics, which has been found by several studies in the last decades (Kümmerer, 2009b). This phenomenon together with an imprudent use of antibiotics is probably the main cause of bacterial resistance found in the environment.

Contribution to the mass of antibiotics in the environment is considered to be from the excretion and disposal of drugs for human and animal use, plant agriculture as well as aquaculture and recently from pharmaceutical production plants. Discharge of antibiotics from production plants have received little attention previously but recently it has been found that in some Asian countries concentrations of up to several $\mathrm{mg} \mathrm{L}^{-1}$ could be found in effluents for single compounds (Larsson et al., 2007; Li et al., 2008). In developed countries a manufacturing plant can also make a significant contribution to total antibiotic concentration in the influent of a sewage

\footnotetext{
National Institute of Drug Quality Control, Vietnam

Hanoi University of Pharmacy, Vietnam

National Research Centre for Environmental Toxicology, University of Queensland, Australia

* Corresponding author (E-mail: anhnguyenkieu@gmail.com)
}

treatment plant, as has been shown only recently for the treatment plant in Oslo (Langford and Thomas, 2009).

With the rapid development of the economy, the consumption and production of antibiotics in Vietnam at a very high rate resulted to, an alarming level of the release of those antibiotics to the environment. However, there are only a few studies investigating the occurrence of antibiotics and antibiotic-resistant bacteria in the environment from different sources (hospital effluents, aquaculture...) (Hoa et al., 2011; Duong et al., 2008; Hoang et al., 2012). No study has yet focus to the source of discharge from pharmaceutical production plants.

Cephalosporins are among the safest and the most effective broad spectrum antibiotics (Péhourcq, 1998). In Vietnam they are probably most prescribed and most produced antibiotics. Measurement of their residues in the aquatic environment is necessary to ensure the quality of the environment, especially in the surrounding of the pharmaceutical production plants. A simple and rapid analytical method is in a demand for analysing those cephalosporins in water. Analytical methods in the literature are either developed for clinical/biological samples (Nemutlu et al., 2009; Péhourcq, 1998) and or using high cost instruments such as LC-MS (Meng et al., 2005) that are not suitable for the environmental water samples. In this study, we aimed to develop a simple and rapid analytical method for the analysis of cefixime, in effluent of a pharmaceutical plant as a tool for regular environmental monitoring program at local level (factory quality control or local environment authority). 


\section{MATERIALS AND METHODS}

\section{Chemicals and reagents}

Cefixime (98.88\% purity, national standard) was obtained from the National Institute for Drug Quality Control (Hanoi, Vietnam). Working standards of cefuroxime sodium, cefadroxil, cefdinir, cefoperazon (other cephalosporin antibiotics) were also obtained from the National Institute for Drug Quality Control (Hanoi, Vietnam). Methanol and acetonitrile (HPLC-grade), dichloromethane, chloroform, diethyl ether, cyclohexane, sodium dihydrophosphate, acid hydrochloric, acid phosphoric were purchased from Merck (Darmstadt, Germany). Deionized water was used throughout the study.

\section{Preparation of standard solutions}

Standard working solution of cefixime was prepared by dissolving appropriate amount of cefixime in deionized water to give concentration of about $50 \mu \mathrm{g} / \mathrm{ml}$. The working solutions of cefuroxime sodium, cefadroxil, cefdinir, cefoperazon also at concentration of $50 \mu \mathrm{g} / \mathrm{ml}$ were obtained directly from the standard stock of the National Institute for Drug Quality Control (Hanoi, Vietnam) and were used for comparison purpose.

A calibration curve was prepared by diluting the working standard of cefixime to obtain a series of solutions with concentrations of 25, 50, 100, 200, 500, 800, $1000,1200 \mathrm{ng} / \mathrm{ml}$ water.

Spike samples were prepared by spiked working solution of cefixime (or of other cephalosporins) to matrix blank samples at appropriate concentrations for validation purposes.

\section{Sample preparation}

Wastewater samples were collected in an effluent system of a pharmaceutical plant located in Hanoi, Vietnam. A series of tests were conducted to find the optimal treatment for the water samples. In general, samples were filtered through a $0.45 \mu \mathrm{m}$ filter paper and then were used directly or were acidified by $\mathrm{HCl} 1 \mathrm{~N}$ to $\mathrm{pH}$ around 3. Samples were then poured into a test tube of $15 \mathrm{~mL}$ before an organic solvent or a mixture of them was added in different ratio for cleaning up purpose. The mixture was well shaken in 10 min by a Vortex device and then was centrifuged in 5 min at the speed of $3000 \mathrm{rpm}$. The aqueous phase was taken and filtered again through a $0.45 \mu \mathrm{m}$ filter paper before analysis. Organic solvents to be tested include acetonitrile, chloroform, dichloromethane, diethyl ether and cyclohexane.

\section{Chromatographic conditions}

Chromatography was performed using a MerckHitachi LiChrom HPLC system equipped with a pump, on-line vacuum degasser, auto-sampler, column oven, and UV-Vis detector (Merck-Hitachi, Darmstadt, Germany). The chromatographic data was analyzed using Multi-system Manager connected to the D7000 Interface to control the HPLC system.

Cefixime and other cephalosporins were separated by a Phenomenex Luna C18 column $(250 \times 4.6 \mathrm{~mm}$; $5 \mu \mathrm{m})$. The oven was kept at $32^{\circ} \mathrm{C}$. After a first screening run to determine the maximum absorbance of cefixime, the UV detector was set at $285 \mathrm{~nm}$ wavelength. Injection volume was set at $200 \mu \mathrm{L}$ to achieve the highest detection limit while still maintain a good separation/peak shape. An initial test of the mobile phase indicated that a suitable mobile would consist of methanol and a phosphate buffer at $\mathrm{pH} 3.2$ (solution of sodium dihydrophosphate $40 \mathrm{mM}$, with $\mathrm{pH}$ adjusted by condensed phosphoric acid), using a gradient program as presented in Table 1.

\section{Data analysis}

Qualitative: Identification of cefixime in the samples (spiked or real) by comparing the retention time and UV spectrum of peaks in chromatographs of tested samples with those of the standards. All data obtained from precision and accuracy tests were analysed according to ICH guideline for method validation (ICH, 2005).

Quantitative: Using linear regression to construct a calibration curve and a corresponding regression equation. Concentrations of cefixime in the tested samples were calculated from this equation.

\section{RESULTS AND DISCUSSIONS}

\section{Optimisation of analytical conditions}

\section{Optimisation of sample preparation}

Collected wastewater samples were acidified at $\mathrm{pH}$ 3 to facilitate the condition of HPLC analytical assay. However a value of $\mathrm{P}_{\mathrm{o} / \mathrm{w}}-0.64$ of cefixime at $\mathrm{pH}$ around 3 hinders the drug from partioning from the aqueous phase into the organic phase. Therefore, samples were treated to remove interference of lipophilic compounds using organic solvents while cefixime was remained in the aqueous phase. A number of solvents including solvent mixtures with different ratios were tested to find an optimal condition, namely simple, less interference, and acceptable recovery.

Samples were first treated with acetonitrile to precipitate proteins in the samples as usually recommended for biological samples (Péhourcq, 1998) and were then treated with single or a mixture of chloroform, dichloromethane and diethyl ether. Table 2 presents organic solvents with different ratios of combination used for elimination of lipophilic contaminants. The combination of acetonitrile and dichloromethane was shown to delivere the best recovery among those mixtures but the use of acetonitrile is not suitable since the maximum recovery was about $80 \%$ (data not shown). It is probably due to the dilution effect of acetonitrile (which is miscible in water) to the sample. Therefore, acetonitrile should be avoided for sample preparation and but immiscible solvents such as chloroform, diethyl ether and cyclohexane were recommended.

It is clear that acidification of the sample, which led to stronger ionic force of cefixime and other cephalosporin antibiotics with an amino group (Péhourcq, 1998), showed an advantage over non-acidification in 
term of keeping the target analyte in the aqueous phase for a higher recovery.

Those results were evaluated together with the chromatograms shown in Fig. 1 to decide which treatment would be used for actual samples. Less interference in the chromatograph (Fig. 1) and a high recovery (Table 1) of acidified samples treated with chloroform (sample/solvent ratio of 5:3 v/v) demonstrated suitability of chloroform as a cleaning solvent. Moreover, good recoveries for 4 other cephalosporin antibiotics were also obtained when treated with chloroform.

Data on the robustness of the sample treatment presented in Table 3 indicate that the selected treatment protocol is suitable to apply for actual wastewater samples and has potential to extend for treating other cephalosporin antibiotics in the sample with recovery value over $93 \%$.

\section{Optimisation of instrumental conditions}

It is usual for a pharmaceutical company to produce different cephalosporin antibiotics at the same period of time. Therefore, it is important for the method to separate and quantify cefixime in the presence of other cephalosporins in the sample background. We have screened a range of different mobile phase parameters (compositions and flow rates) and injection volumes to find the optimal chromatographic conditions as stated in previous sentence.

A simple isocratic mobile phase was tested against a gradient program in this study. Although simple the isocratic condition did not provide satisfactory outcomes: cefixime was not completely separated from other cephalosporins and the peak stretched as well as asymmetric (Fig. 2a). Meanwhile, the gradient program successfully separated cefixime from other peaks and the cefixime peak was symmetric (Fig. 2b). The detailed gradient program was provided in Table 1.

For a simple method, increasing injection volume is an approach to improve the limit of detection. However, care should be taken to ensure the quality of the target peak (symmetric) and the overall chromatogram (level of noise). After testing different injection volumes in the range of $20-200 \mu \mathrm{l}$, it was found that the volume of $200 \mu \mathrm{l}$ is suitable for this method.

Although it is reviewed that cefixime can be detected in different UV wavelength (Péhourcq, 1998), a spectrum screen from 200-350 nm for the sample

Table 1. Gradient program of the mobile phase

\begin{tabular}{cccc}
\hline Time (min) & MeOH (\%) & $\begin{array}{c}\text { Phosphate buffer } \\
\text { solution (\%) }\end{array}$ & $\begin{array}{r}\text { Flow rate } \\
(\mathrm{ml} / \mathrm{min})\end{array}$ \\
\hline 0 & 18 & 82 & 1.0 \\
6 & 45 & 55 & 1.0 \\
13 & 55 & 45 & 0.85 \\
14 & 18 & 82 & 0.85 \\
\hline
\end{tabular}

Table 2. Different organic solvent with different ratio of samples and solvents used for sample treatment

\begin{tabular}{cccc}
\hline \multirow{2}{*}{ Solvent } & $\begin{array}{c}\text { Sample:solvent } \\
\text { volume ratio }\end{array}$ & $\begin{array}{c}\text { Non-acidified } \\
\text { sample }\end{array}$ & $\begin{array}{c}\text { Acidified } \\
\text { sample (pH 3) }\end{array}$ \\
\cline { 3 - 4 } Diethyl ether & $4: 4$ & 70.7 & Recovery (\%) \\
\hline \multirow{2}{*}{ Chloroform } & $5: 3$ & 78.3 & 80.5 \\
& $4: 4$ & 41.1 & 93.5 \\
Cyclohexane & $5: 3$ & 40.9 & 96.8 \\
& $5: 3$ & 18.1 & 48.6 \\
& & 16.5 & 47.1 \\
\hline
\end{tabular}

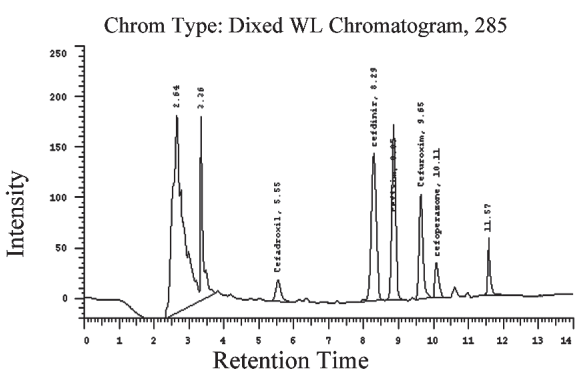

(a) Sample treated with diethyl ether $(5: 3)$

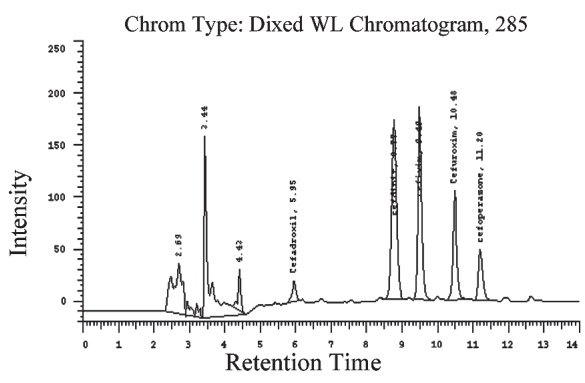

(b) Sample treated with chloroform $(5: 3)$

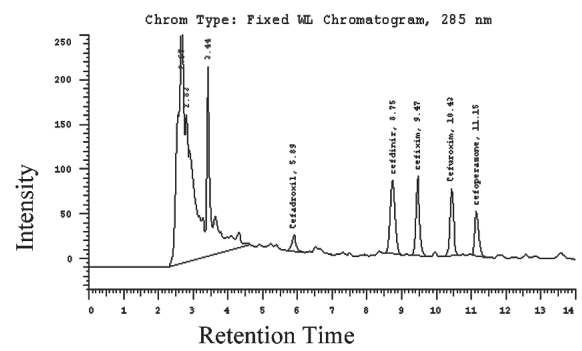

(c) Sample treated with cyclohexane $(5: 3)$

Fig. 1. Chromatograms of acidified extracts using different solvents. 
Table 3. Robustness of sample treatment for different cephalosporin antibiotics

\begin{tabular}{cccccc}
\hline & \multicolumn{5}{c}{ Recovery (\%)* } \\
\cline { 2 - 6 } & Cefixime & Cefdinir & Cefadroxil & Cefuroxime & Cefoperazone \\
\hline \multirow{2}{*}{ Ave } & 96.0 & 100.2 & 101.5 & 96.9 & 93.8 \\
Sdev & 0.55 & 0.59 & 1.35 & 1.52 & 0.30 \\
RSD & 0.57 & 0.59 & 1.33 & 1.57 & 0.32 \\
\hline
\end{tabular}

* 6 samples were used for each test and the average value was used.

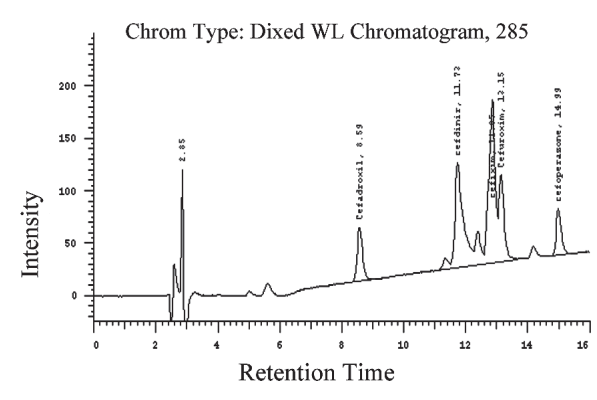

a. Isocratic mobile phase

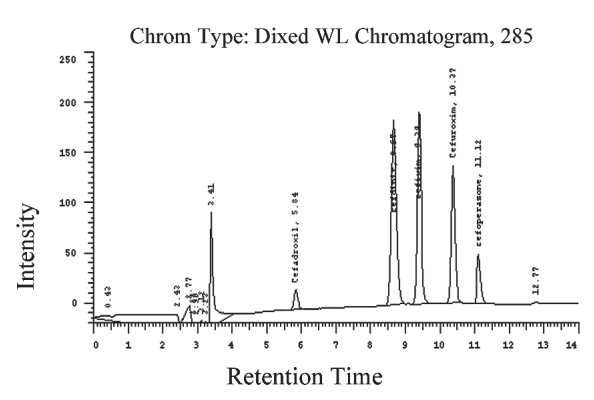

b. Gradient mobile phase

Fig. 2. Comparison of different mobile phase programs.

extracts of this study indicated the maximum absorbance at $285 \mathrm{~nm}$. It is in agreement with another study by Khan et al. (2011) in which the response at $285 \mathrm{~nm}$ was concluded to give a maximum absorbance of cefixime while minimised extraneous peaks. Thus, a wavelength of $285 \mathrm{~nm}$ was selected for cefixim determination.

\section{Method validation}

After the optimisation of all parameters, the method was validated according to the ICH guideline for method validation (ICH, 2005). The matrix in use was the wastewater from a pharmaceutical production factory in Vietnam.

The selectivity of the method was evaluated by comparing a retention time of cefixime peak and aspectra of peaks between standard and test samples. The linearity of the calibration curve was assessed based on the regression between cefixime concentrations and the

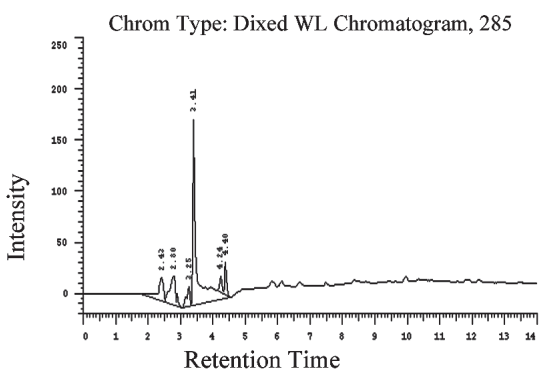

a. Blank sample

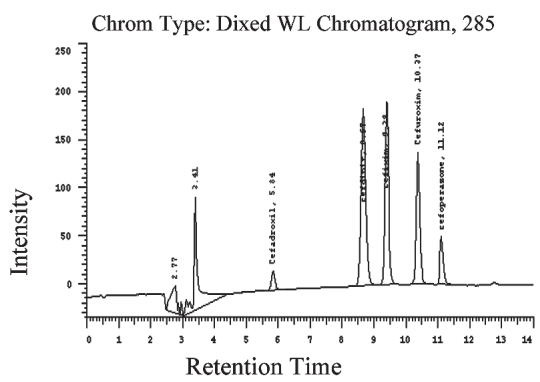

c. Sample containing 5 cephalosporins

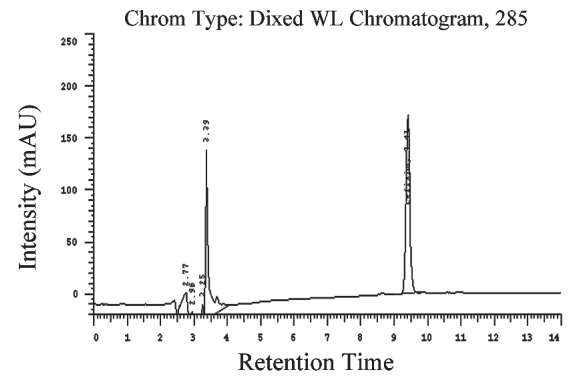

b. Spiked sample with cefixime

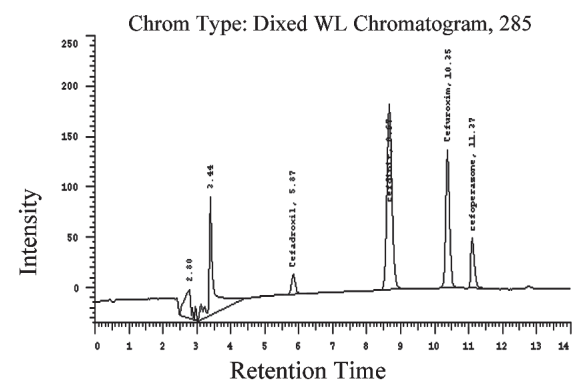

d. Sample containing 4 cephalosporins

(without cefixime)

Fig. 3. Chromatograms of samples during optimisation of instrumental conditions. 
Table 4. Results of the method validation

\begin{tabular}{|c|c|c|}
\hline Parameter & AOAC recommended threshold & Results \\
\hline \multirow{3}{*}{ Selectivity } & $\begin{array}{l}\text { Retention time }\left(t_{\mathrm{R}}\right) \text { of peak on chromatogram of test sample } \\
\text { coincide with that of standard sample. }\end{array}$ & $\begin{array}{l}t_{\mathrm{R}} \text { standard } \sim 9.43 \mathrm{~min} \\
t_{\mathrm{R}} \text { test sample } \sim 9.52 \mathrm{~min}\end{array}$ \\
\hline & $\begin{array}{l}\text { No peak on chromatogram of blank sample at the same } \\
\text { retention time with the target analyte }\end{array}$ & $\begin{array}{l}\text { There was no peak in the } \\
\text { chromatogram of blank sample at the } \\
\text { retention time of cefixime }\end{array}$ \\
\hline & $\begin{array}{l}\text { UV-VIS spectrum of cefixime in standard and test samples } \\
\text { gave an } S I>0.99\end{array}$ & $S I=0.9993$ \\
\hline \multirow{3}{*}{$\begin{array}{l}\text { System } \\
\text { suitability }\end{array}$} & RSD of peak area $\leq 2.0 \%(n=6)$ & $1.41 \%$ \\
\hline & $\mathrm{RSD}$ of $t_{\mathrm{R}} \leq 1.0 \%(n=6)$ & $0.46 \%$ \\
\hline & Resolution of cefixime peak and a close peak (cefnidir) $>1.5$ & $R_{\mathrm{s}}=1.6$ \\
\hline \multirow{4}{*}{ Linearity } & Linear range & $22.98-1103.14 \mathrm{ng} / \mathrm{ml}$ \\
\hline & $r \geq 0.998$ & $r=0.99998$ \\
\hline & Slope & 0.001803 \\
\hline & Intercept & 0.003693 \\
\hline \multirow{3}{*}{$\begin{array}{l}\text { Accuracy } \\
\text { (recovery) }\end{array}$} & @ low level $\approx 70$ ng/ml: $60-115 \%$ & $100.2-106.0 \%$. Ave $=103.0 \%$ \\
\hline & @ medium level $\approx 500$ ng/ml: $80-110 \%$ & $97.4-104.5 \% . A v e=103.0 \%$ \\
\hline & @ high level $\approx 1000$ ng/ml: $80-110 \%$ & $97.7-104.7 \%$. Ave $=101.5 \%$ \\
\hline \multirow{3}{*}{ Precision } & @ low level $\approx 70 \mathrm{ng} / \mathrm{ml}: R S D \leq 21.0 \%(n=6)$ & $1.50 \%$ \\
\hline & @ medium level $\approx 500 \mathrm{ng} / \mathrm{ml}: R S D \leq 15.0 \%(n=6)$ & $1.04 \%$ \\
\hline & @ high level $\approx 1000 \mathrm{ng} / \mathrm{ml}: R S D \leq 15.0 \%(n=6)$ & $1.64 \%$ \\
\hline \multirow{3}{*}{ Reproducibility } & $@$ low level $\approx 70 \mathrm{ng} / \mathrm{ml}: R S D \leq 21.0 \%(n=12)$ & $1.35 \%$ \\
\hline & $@$ medium level $\approx 500 \mathrm{ng} / \mathrm{ml}: R S D \leq 15.0 \%(n=12)$ & $2.61 \%$ \\
\hline & @ high level $\approx 1000 \mathrm{ng} / \mathrm{ml}: R S D \leq 15.0 \%(n=12)$ & $2.14 \%$ \\
\hline Limit of detection & $\begin{array}{l}\text { Concentration at which cefixime response is higher than } 3 \\
\text { times background signal }\end{array}$ & $6.68 \mathrm{ng} / \mathrm{ml}$ \\
\hline Limit of quantification & $\begin{array}{l}\text { Concentration at which cefixime response is higher than } 10 \\
\text { times background signal }\end{array}$ & $22.0 \mathrm{ng} / \mathrm{ml}$ \\
\hline
\end{tabular}

areas of cefixime peak in the chromatogram. The limit of detection of the method was calculated from the slope of the calibration curve and the standard deviation of the response.

The precision and the accuracy of the method were assessed at three concentration levels (low, medium and high level). The results of the validation tests together with the recommended thresholds of AOAC (AOAC, 2011) were presented in Tables 4 and Fig. 3.

The results showed that the newly developed method has good selectivity with high precision and accuracy (according to AOAC standards). The linearity ranges in 3 orders of magnitude which is suitable to measure cefixime in wastewater because of the large variation of cefixime concentration in this media.

Additionally, the stability of test samples was also evaluated after storing samples at ambient temperature for 4 and 24 hours and at $-20^{\circ} \mathrm{C}$ for 5 and 10 days. The results of the stability test were presented in Table 5 . The stability test indicated that cefixime could be preserved in the samples in a short period of time at ambient temperature $(1.5 \%$ difference) but would start to
Table 5. Results of the stability test

\begin{tabular}{ccc}
\hline Storage condition & Storage time & \% difference* \\
\hline \multirow{2}{*}{ Ambient temperature } & After 4 hours & -1.5 \\
& After 24 hours & -5.8 \\
$-20^{\circ} \mathrm{C}$ & After 5 days & -2.8 \\
& After 10 days & -3.8 \\
\hline
\end{tabular}

* 6 samples were used for each test and the average value was used.

degrade after 24 hours (over 5\% difference) while the freezer condition of $-20^{\circ} \mathrm{C}$ can keep the samples well preserved for at least 10 days.

\section{Applications to real samples}

Actual wastewater samples were taken from the sewer of a pharmaceutical production company during the period where production of cefixime happened. Sampling was carried out in 3 consecutive days in August 2013 and samples were transferred directly to 


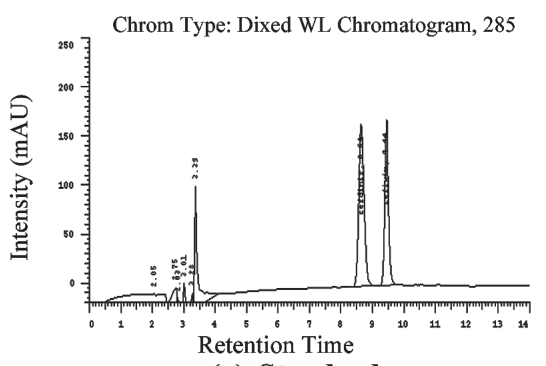

(a) Standard

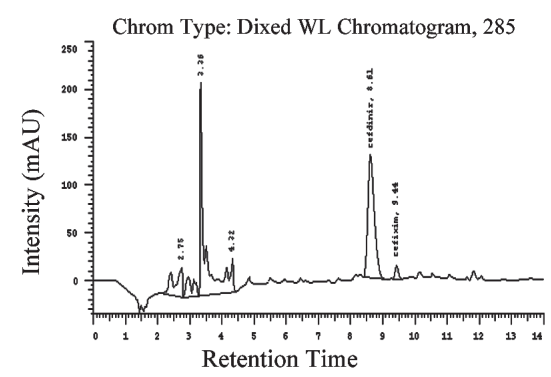

(b) Wastewater

Fig. 4. Chromatograms of standard and actual wastewater samples taken from the sewer.

Table 6. Concentrations of cefixime in actual samples

\begin{tabular}{cccc}
\hline Day & Replicate & $\begin{array}{c}\text { Cefixime concentration } \\
\text { (ng/ml) }\end{array}$ & $\begin{array}{c}\text { Average value } \\
\text { (ave } \pm \text { st dev) }\end{array}$ \\
\hline \multirow{2}{*}{ I } & 1 & 29.96 & $30.9 \pm 2.8$ \\
& 2 & 28.71 & \\
\hline \multirow{2}{*}{ II } & 3 & 34.11 & $43.3 \pm 1.1$ \\
& 1 & 42.12 & \\
\hline \multirow{2}{*}{ III } & 3 & 43.70 & $19.2 \pm 0.6^{*}$ \\
& 2 & 44.18 & \\
\hline
\end{tabular}

* concentration at the level close to the limit of quantification but the results of triplicate samples confirmed the presence of cefixime.

the laboratory for analysis.

Samples were treated and analysed using the method described above. Results were presented in Table 6 and Fig. 4. The chromatogram (with spiked cefdinir as reference compound) showed a clearly separated peak of cefixime in the samples. The concentrations of cefixime measured in those 3 samples were above the detection limit and may pose some risk to the environment. Therefore, the newly developed method is applicable to measure the residue of cefixime in wastewater of the pharmaceutical industry.

\section{DISCUSSION}

Preventing the occurrence of antibiotic resistant bacteria is an important task in the cause of protecting human and animal health. Monitoring the residue of antibiotics in the environment, especially the aquatic environment would help authorities to tighten their regulation on waste water treatment. To carry out this task in developing countries where analytical cost is an obstacle for many monitoring programs, a simple (low cost) and rapid analytical method is needed. The newly developed method has satisfied those criteria because:

1. Sample treatment by chloroform is simple, rapid and cheap but the recovery and robustness are high. Additionally, this protocol can also be applied to treat samples containing 4 other cephalosporins (cefadrox- ile, cefdinir, cefuroxime and cefoperazone) with recovery of more than $90 \%$.

2. The separation is carried by a HPLC-UV system which is widely equipped in even small laboratory.

3. The limit of detection of this method is considered relatively high but is capable of detecting cefixime in actual wastewater samples. However, further work is needed to lower the limit of detection to meet the common standard of $1 \mathrm{ng} / \mathrm{ml}$.

\section{REFERENCES}

AOAC 2011, Standard Format and Guidance for AOAC Standard Method Performance Requirement (SMPR) Documents

Duong, H. A., N. H. Pham, H. T. Nguyen, T. T. Hoang, H. V. Pham, V. C. Pham, M. Berg, W. Giger and A. C. Alder 2008 Occurrence, fate and antibiotic resistance of fluoroquinolone antibacterials in hospital wastewaters in Hanoi, Vietnam. Chemosphere 72(6): 968-973

Hoa, P. T. P., S. Managaki, N. Nakada, H. Takada, A. Shimizu, D. H. Anh, P. H. Viet, and S. Suzuki 2011 Antibiotic contamination and occurrence of antibiotic-resistant bacteria in aquatic environments of northern Vietnam. Science of the Total Environment 409(15): 2894-2901

Hoang, T. T. T., L. T. C. Tu, N. P. Le, Q. P. Dao and P. H. Trinh 2012 Fate of fluoroquinolone antibiotics in Vietnamese coastal wetland ecosystem. Wetlands Ecology and Management 20(5): 399-408

ICH Q2(R2) Validation of analytical procedures 2005 Text and Methodolody. Analytical Method Validation

Khan, A., Z. Iqbal, M. I. Khan, K. Javed, A. Khan, L. Ahmad, Y. Shah and F. Nasir 2011 Simultaneous determination of cefdinir and cefixime in human plasma by RP-HPLC/UV detection method: Method development, optimization, validation, and its application to a pharmacokinetic study. Journal of Chromatography B 879(24): 2423-2429

Kümmerer, K. 2009 Antibiotics in the aquatic environment - A review - Part I. Chemosphere $\mathbf{7 5}$ (4): 417-434

Kümmerer, K. 2009 Antibiotics in the aquatic environment - A review - Part II. Chemosphere 75(4): 435-441

Larsson, D. G. J., C. de Pedro, and N. Paxeus 2007 Effluent from drug manufactures contains extremely high levels of pharmaceuticals. Journal of Hazardous Materials 148(3): 751-755

Langford, K. H. and K. V. Thomas 2009 Determination of pharmaceutical compounds in hospital effluents and their contribution to wastewater treatment works. Environment International 35(5): 766-770 
Lin, A. Y. C., T. H. Yu and C. F. Lin 2008 Pharmaceutical contamination in residential, industrial, and agricultural waste streams:

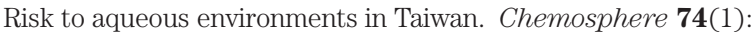
$131-141$

Meng, F., X. Chen, Y. Zeng and D. Zhong 2005 Sensitive liquid chromatography-tandem mass spectrometry method for the determination of cefixime in human plasma: Application to a pharmacokinetic study. Journal of Chromatography $B$ 819(2): 277-282
Nemutlu, E., S. Kır, D. Katlan and M. S. Beksaç 2009 Simultaneous multiresponse optimization of an HPLC method to separate seven cephalosporins in plasma and amniotic fluid: Application to validation and quantification of cefepime, cefixime and cefoperazone. Talanta $\mathbf{8 0}(1): 117-126$

Péhourcq, F. and C. Jarry 1998 Determination of third-generation cephalosporins by high-performance liquid chromatography in connection with pharmacokinetic studies. Journal of Chromatography A 812(1-2): 159-178 